\title{
SIMPLES NACIONAL: ANÁLISE DA CONSTITUCIONALIDADE DAS EXCLUSÕES SETORIAIS
}

Guilherme Adolfo dos Santos Mendes

Professor Doutor e orientador pleno no Programa de Mestrado da Faculdade de Direito de Ribeirão Preto da Universidade de São Paulo (FDRP-USP).

\section{Resumo}

A Constituição Federal determina o tratamento jurídico favorecido, inclusive e, sobretudo, no campo das obrigaçóes tributárias, para as pequenas empresas, sem estabelecer qualquer exceção explícita. Nada obstante, todas as leis que introduziram regras tributárias mais benéficas orientadas por esse preceito superior discriminaram empreendimentos diminutos em razão do setor econômico de atuação.

O atual regramento, chamado "Simples Nacional", consta da Lei Complementar $\mathrm{n}^{\circ}$ 123/06, mas dele náo podem se beneficiar as menores unidades produtivas de diversos setores, tais como o automobilístico, o de transporte de passageiros, o de energia e o de fabricação de armas, bebidas e produtos de tabaco.

Ao demonstrar a erronia dos argumentos a favor de tais exclusóes, o artigo sustenta que nenhuma dessas previsóes encontra amparo constitucional. Ademais, com base numa análise crítica do direito positivo, demonstra-se que o intento oculto almejado com as exclusōes foi o de reservar para o grande capital, em detrimento das iniciativas de menor porte, setores econômicos de elevada lucratividade.

\section{Palavras-chave}

Simples Nacional; Pequenas Empresas; Livre Concorrência; Setores Econômicos.

\section{Abstract}

The Constitution defines the favored legal treatment for small businesses without making any explicit exception, including and especially for tax obligations. Nevertheless, all the laws, which have introduced tax benefits guided by this higher provision, have discriminated small companies due to the economic sector of activity.

Known as "National Simple" and introduced by the Complementary Law No. 123/06, the current legislation did not extend its benefits to small production units of a 
number of industries, such as the automotive industry, the passenger transport industry, the energy industry and the industry of manufacture of weapons, beverages and tobacco products.

By demonstrating the mistakes of the arguments in favor of such exclusions, the article holds up that none of these provisions meets constitutional standards. Furthermore, based on a critical analysis of the Positive Law, it is shown that the hidden desire behind the exclusions was to keep the economic sectors of high profitability under control of big corporations to the detriment of smaller initiatives.

\section{Key words}

National Simple; Small Business; Free Competition; Economic Sectors.

\section{Introdução}

O presente artigo tem por objetivo analisar a constitucionalidade da proibição de pequenas empresas optarem pelo atual regime favorecido de tributação (Simples Nacional) em função do seu ramo de atividade.

Para atingir tal desiderato, analisaremos o perfil constitucional do tratamento jurídico favorecido, o histórico das exclusóes informadas por critérios setoriais e a coerência das razóes que poderiam ter levado o legislador a promover as atuais exclusóes nos setores automobilístico, de transporte de passageiros, de energia, e de fabricação de armamento, bebidas e cigarros.

\section{0 Tratamento Constitucional Favorecido para as Pequenas Empresas}

Só três países no mundo dispensam, em seu Diploma Súpero, regras específicas às empresas de pequeno porte. O Brasil é um deles (os outros são Portugal ${ }^{1}$ e Peru $^{2}$ ). Ademais, nossa Constituição é a única a determinar expressamente o favorecimento jurídico dessa classe de empresas no âmbito das obrigaçóes tributárias.

Todavia, a vanguarda, sob o aspecto normativo-hierárquico, não foi fruto de pioneirismo legislativo, nem é garantia de liderança na implementação de mecanismos eficazes de estimulo aos modestos empreendimentos. Antes de nós, diversas outras naçóes já implementavam importantes medidas de fomento às suas menores unidades produtivas,

1 São três os dispositivos da Constituição Portuguesa que versam sobre a matéria, quais sejam: art. 86, item "1"; art. 100, alínea "d"; e art. 293, item 2.

$2 \mathrm{Na}$ parte final do art. 59 da Constituição Peruana está assim estabelecido: "El Estado brinda oportunidades de superación a los sectores que sufren cualquier desigualdad; en tal sentido, promueve las pequeñas empresas en todas sus modalidades”. 
com destaque para Itália, Japão e Estados Unidos ${ }^{3}$, e ainda hoje estamos aquém das mais modernas políticas públicas e disciplinas jurídicas de incentivo às microempresas e às empresas de pequeno porte (Mpes).

Apesar da peculiar condição de portarmos, no ápice da nossa ordem jurídica, normas específicas de favorecimento aos de menor dimensão empresarial, não ocupamos posição igualmente avançada no plano dos diplomas infraconstitucionais e, menos ainda, no patamar das realizaçôes concretas.

Não podemos negar, contudo, o progresso nacional na questão, especialmente, em razáo de termos elevado o tema ao nível das preocupaçóes de índole constitucional, providência que foi capaz de impulsionar várias outras ações legiferantes igualmente louváveis, dentre as quais, o "Simples Nacional" estabelecido pela Lei Complementar no 123/06.

Nossa investigação, por isso, principia pelo exame do texto constitucional. Nele, localizamos cinco conjuntos de dispositivos que regem o tratamento jurídico favorecido das Mpes; uns originários da CF, outros posteriormente introduzidos no Texto Excelso por emendas constitucionais.

No seu texto original, a CF já continha o inciso IX do art. 170, o art. 179 e o art. 47 do ADCT. O primeiro dispositivo, cuja redação foi alterada pela EC nº 6/95, estabelece como princípio da ordem econômica "o tratamento favorecido para as empresas de pequeno porte constituídas sob as leis brasileiras e que tenham sua sede e administração no País". Esse princípio é balizador de todos os demais dispositivos constitucionais e, evidentemente, do conjunto completo das prescriçóes jurídicas. O preceito do "tratamento favorecido" governa inteiramente o percurso de positivação do direito que trata as questóes atinentes às pequenas empresas.

$\mathrm{O}$ art. 179, por seu turno, prevê regra programática, dirigida a todos os entes da federação (União, Estados, Distrito Federal e Municípios), a lhes impor o dever de dispensar às microempresas e empresas de pequeno porte tratamento jurídico diferenciado (diferenciação que não pode ser uma qualquer, mas sim aquela destinada a favorecer os pequenos em face do preceito norteador estampado no já referido art. 170, inciso IX) por meio de três formas: supressão, redução e simplificação de obrigações. Ademais, expressamente, prescreve que a diferença favorável de tratamento deve ser estabelecida também na seara tributária.

3 A preocupação norte americana com o tratamento das pequenas empresas, por exemplo, remonta às leis antitrute editadas ainda do século XIX. Vale ainda mencionar a criação da primeira comissão parlamentar para estudar as condiçóes das pequenas empresas, constituída pelo Senado Americano, em 1940, por iniciativa do Senador James Murray (VINYARD, 1966, p. 370) e o "Small Business Administration" (SBA) criado pelo "Small Business Act" de 1953, o qual é até os dias atuais o principal órgão público responsável pelo desenvolvimento e aplicação de políticas de incentivo aos pequenos empreendimentos. 
Dos três dispositivos originários da CF, o art. 47 do ADCT é o menos citado nos trabalhos acadêmicos. Isso se deve ao seu caráter casuístico, pois estabelece uma regra de exclusão de correção monetária, mas apenas para determinados empréstimos outrora concedidos às Mpes.

Em 2003, a EC no 42 introduziu novos dispositivos atinentes ao tema do tratamento favorecido destinados a regular matéria tributária. Ao modificar o art. 146 da CF, a referida EC atribuiu à lei complementar dois conjuntos de competências: um, previsto na alínea "d" do inciso III, para definir o tratamento favorecido; outro, estabelecido no parágrafo único e seus incisos, para instituir um regime único de arrecadação de impostos e contribuições federais, estaduais e municipais. Inseriu ainda, no ADCT, o art. 94, que determina a revogação dos tratamentos jurídicos especiais estabelecidos por cada um dos Entes políticos tấo logo entre em vigor o regime único.

Por fim, a Emenda Constitucional no 47/05, ao alterar a redaçáo do $\$ 9^{\circ}$ do art. 195 da CF, autorizou o legislador a diferenciar, em função do porte da empresa, as alíquotas e bases de cálculo das contribuiçôes à Seguridade Social exigidas do empregador. Apesar de não haver expresso estabelecimento do sentido da diferenciação, em face do preceito norteador de tratamento favorecido às pequenas empresas estampado no art. 170, inciso IX, é notório que não podem ser as grandes empresas e os conglomerados econômicos os destinatários de benesses tributárias estabelecidas segundo o critério do porte empresarial.

O tratamento jurídico favorecido para as pequenas empresas, como previsto na Constituição Federal, está em perfeita harmonia com o seu primado maior de isonomia na sua feição substancial: tratar igualmente os iguais e desigualmente os desiguais na medida das suas desigualdades. Na verdade, pode ser considerado uma medida concretizadora efetiva do axioma da igualdade. Afinal, são muitas e diversificadas as desvantagens das Mpes em relação às empresas de maior porte, tais como (i) dificuldade e os altos custos para obtenção de financiamento, (ii) custos administrativos proporcionalmente maiores para o cumprimento das diversas obrigaçóes legais, inclusive tributárias, e (iii) dificuldades para obter informaçôes sobre novas tecnologias (OECD, 1994, p. 3), a exigirem que o direito contrabalance tamanho desnível.

Em artigo no Jornal Folha de S.Paulo, Roque Pellizzaro Júnior, Presidente da Confederação Nacional de Dirigentes Lojistas, ao criticar o avanço aniquilador das grandes redes de varejo sobre os pequenos comerciantes, com aval inclusive das políticas governamentais na área tributária, informa que as administradoras de cartôes de crédito chegam a cobrar de 30\% a 40\% a mais das Mpes que dos grandes conglomerados (2011).

Até o crescimento das vendas, surpreendentemente, é um fator apontado pelos autores como passível de levar os pequenos empreendimentos ao infortúnio. RESNIK aponta 
os diversos riscos que uma expansão muito rápida pode gerar, como a perda de controle sobre os custos, as margens e o fluxo de caixa (1990, p. 198-223).

O tratamento favorecido, contudo, não se limita a buscar a igualdade entre as diversas empresas quanto ao seu porte, muito menos corresponde apenas a cuidar de desvalidos econômicos. O regime jurídico especial para as pequenas unidades produtivas é instrumento para a consecução de diversos e relevantes intentos constitucionais. De um lado, tem por escopo preservar as bases capitalistas de produção constantemente corroídas pelas distorçóes do modelo liberal, sendo uma delas a concentração econômica que afasta o mercado real do modelo ideal da concorrência perfeita de máxima eficiência; de outro, visa atender os mais variados direitos da ordem social por meio da ampliação das oportunidades de trabalho.

\section{Histórico das Exclusões Setoriais}

A nossa Constituição não só é uma das únicas três, em todo o mundo, a contemplar o tratamento favorecido para as pequenas empresas, tratamento este informado por escopos da mais elevada envergadura. É, de longe, a mais prolífera. Nada obstante, em nenhum dos seus diversos dispositivos, há sequer uma só referência à exclusão de pequenas empresas em razão do seu tipo de atividade.

Todavia, as leis inferiores, ao concretizarem o tratamento constitucionalmente determinado, sempre estabeleceram discriminações a pequenos empreendimentos em razão do seu setor econômico de atuação. Na verdade, até antes da atual Constituição, em 1984, quando o tratamento favorecido surgiu no patamar infraconstitucional por meio da edição do então chamado Estatuto das Microempresas (Lei 7.256/84), foram prescritas atividades cujos pequenos agentes econômicos eram excluídos dos incentivos legais. Eram exemplos: prestadores de serviço de armazenagem e depósito de produtos de terceiros, e os prestadores de serviço de propaganda e publicidade (art. $3^{\circ}$, inciso V).

As leis editadas já sob a égide na nossa atual Constituição não alteraram esse panorama excludente; pelo contrário, o intensificaram. O primeiro diploma normativo de abrangência nacional foi a Lei no $8.864 / 94$, a qual, apesar de ter tido o escopo de estabelecer "normas para as microempresas (ME), e Empresas de Pequeno Porte (EPP), relativas ao tratamento diferenciado e simplificado, nos campos administrativo, fiscal, previdenciário, trabalhista; creditício e de desenvolvimento empresarial”, de tão acanhada, nem sequer foi tratada pelo próprio legislador como um estatuto. No campo tributário, não estabeleceu nenhuma medida concreta. Desse modo, continuaram em vigor as isençóes para as microempresas previstas no Estatuto de 1984, enquanto as empresas não tão mirradas, mas ainda assim pequenas, continuaram sem qualquer medida tributária favorável, a despeito das disposiçóes constitucionais de 1988. 
Nada obstante, o artigo $3^{\circ}$ da referida lei também contemplava exclusóes setoriais. Esse artigo, contudo, nem sequer chegou a entrar em vigor em face do veto presidencial, cujas razóes foram assim expostas:

A título de elencar as pessoas jurídicas excluídas do regime especial que se pretende inaugurar, o artigo, na verdade, constitui um retrocesso em face da legislaçáo anterior, notadamente o art. $3^{\circ}$ da Lei no 7.256 de 1984 e art. 51 da Lei 7.713, de 1988, os quais definiram com precisão quais as empresas, em função da sua natureza jurídica e do ramo de atividade, que poderiam usufruir das vantagens do enquadramento como microempresa. A permanecer a redação proposta no art. $3^{\circ}$ do projeto de lei, poderão abrigar-se sob o espectro de "microempresa" um leque de pessoas jurídicas cujas características não admitem dito tratamento e que passarão a competir, em condições desiguais, com aquelas que realmente necessitam do incentivo do Estado para se desenvolverem.

É relevante destacar que a redação do dispositivo reduzia o número de microempresas excluídas do tratamento favorecido, o que foi considerado, nas razóes do veto, um "retrocesso", sob o vago argumento de que, devido a suas características competiriam em condiçóes de desigualdade com as já anteriormente beneficiadas.

Ora, é interessante notar que nenhuma dessas características foi apontada e também não se especificou como microempresas de um setor poderiam ser capazes de competir de forma abusiva com as de outro setor. Não nos parece, pois, que essa tenha sido, de fato, a real razão do veto.

No campo das obrigaçóes tributárias federais, o primeiro diploma com o escopo de promover o tratamento favorecido também para as pequenas, e não só para as microempresas, foi a Medida Provisória no 1.526, de 05 de novembro de 1996, convertida, sem demora, na Lei no 9.317, de 05 de dezembro de 1996. Essa lei teve por finalidades principais dispor, em âmbito federal, "sobre o regime tributário das microempresas e das empresas de pequeno porte e instituir o Sistema Integrado de Pagamento de Impostos e Contribuiçóes das Microempresas e das Empresas de Pequeno Porte - SIMPLES”. O referido sistema correspondia a um regime opcional e estruturado para unificar o recolhimento de até 6 (seis) tributos federais (Imposto de Renda da Pessoa Jurídica - IRPJ, Contribuição Social sobre o Lucro Líquido - CSLL, Programa de Integração Social - PIS, Contribuição para o Financiamento da Seguridade Social - Cofins, Imposto sobre Produtos Industrializados - IPI, e Contribuição Previdenciária Patronal - CPP) por meio da aplicação de percentuais sobre a receita bruta mensal, percentuais estes compostos por parcelas relativas a cada um dos tributos integrados. Foi estabelecida também a hipótese de incorporação do Imposto sobre Circulação de Mercadoria e Serviços (ICMS) e do Imposto sobre Serviços (ISS) por meio de convênio, respectivamente, com Estados e Municípios, os quais 
tinham direito ao repasse dos seus recursos, vedada qualquer possibilidade de retenção. Desse modo, por meio de um único pagamento apurado à luz de regras previstas numa só codificação, as micro e pequenas empresas optantes podiam extinguir as obrigaçôes de até oito tributos, sem prejudicar a aplicaçáo de previsóes específicas atinentes a cada uma dessas exações, como as de caráter financeiro.

O Simples Federal foi, sob muitos aspectos, um avanço em relação à sistemática anterior do Estatuto de 1984. Além de outras tantas medidas que poderiam ser citadas, vale destacar ter inaugurado a adoção de incentivos fiscais federais endereçados às pequenas empresas, os quais passaram a ser graduais. Ao contrário do sistema anterior, que demarcava apenas um único patamar de desoneraçóes e, por conseguinte, estabelecia também um degrau elevado de encargos entre as empresas que se situavam próximas da fronteira entre a zona favorecida e a região das múltiplas e complexas obrigaçóes, o Simples Federal foi estruturado com 22 (vinte e dois) patamares de reduçôes tributárias inversamente proporcionais ao porte da empresa.

Todavia, na transição do Estatuto de 1984 para o Regime Integrado de 1996, houve substancial incremento do rol de atividades excluídas do tratamento tributário favorecido. Dentre outros exemplos, passaram a não gozar de incentivos tributários federais as micro e pequenas empresas atuantes nas atividades de vigilância, limpeza, conservação e locação de mão-de-obra; na área financeira, a lista de exclusões deixou de abarcar exclusivamente as empresas que realizavam operaçóes de câmbio, seguro e distribuição de títulos e valores mobiliários, para se estender a praticamente toda sorte de empresas do setor.

Posteriormente, ampliaram-se ainda mais as atividades econômicas cujas empresas não mais poderiam se favorecer do tratamento diferenciado dispensado às Mpes. A Medida Provisória no 2.189-49/01 passou a excluir os fabricantes de bebidas e os de produtos de tabaco, setores que serão analisados nos tópicos seguintes.

\section{As Atuais Exclusões Setoriais}

O estatuto das micro e pequenas empresas hoje em vigor foi veiculado pela Lei Complementar $n^{\circ} 123 / 06$. Esse diploma, ao estabelecer um regime unificado de favorecimento tributário, denominado "Simples Nacional", para abarcar, sob as mesmas regras supostamente mais benéficas aos seus destinatários, tributos federais, estaduais e municipais, substituiu, não só o Simples Federal, mas todos os sistemas implantados por cada um dos entes que formam a organização política brasileira.

A instituição do "Simples Nacional" é apontada por alguns como a alteração legislativa de cunho tributário mais importante desde a promulgação da atual Constituiçãó .

4 Marins \& Bertoldi, ao analisarem o "Simples Nacional", afirmaram: "Somos da opiniāo de que este regime fiscal especial representa, seguramente, a mais importante iniciativa de 'reforma tributária' 
De fato, a sua edição, bem como a da Emenda Constitucional $n^{\circ} 42 / 03$, que a precedeu e lhe deu esteio, representaram mudanças significativas e paradigmáticas no arcabouço jurídico-tributário nacional. Todavia, não estão imunes a críticas. Pelo contrário. Sob muitos aspectos, esse conjunto normativo pode ser considerado um retrocesso em matéria de favorecimento tributário das menores unidades produtivas por, dentre outras razóes, ter ampliado a relação de atividades cujas Mpes deixaram de ser destinatárias das medidas tributárias incentivadoras.

Como exemplo, na sistemática anterior do Simples Federal com as modificaçôes introduzidas a partir da Medida Provisória no 1.991-15, de 10 de março de 2000, todas as pequenas empresas importadoras podiam gozar do regime favorecido. No Simples Nacional, contudo, foram excluídos os importadores de automóveis, motocicletas e combustíveis (art. 17, VIII e IX, da Lei Complementar no 123/06). De igual sorte, os pequenos fabricantes de armamento e explosivos gozavam dos incentivos do Simples Federal, mas passaram a não usufruir de qualquer mitigação das suas obrigaçóes tributárias com a implantação do Simples Nacional.

A exclusão em razão da atividade desenvolvida, contudo, não se justifica. Ao revés de ampliar os setores econômicos, cujas Mpes devem se sujeitar às mesmas obrigaçóes tributárias a que estão submetidas as empresas de maior porte, o legislador complementar deveria nortear suas medidas para eliminar toda e qualquer exclusão do Simples Nacional orientada por critérios setoriais.

A doutrina, acertadamente, há muito tempo, tem criticado diversas dessas exclusôes, mas, em relação a algumas, como as do setor de cigarro, fumo e bebida, manifesta-se concordante, posição com a qual, pelos fundamentos que apresentaremos a seguir, não nos alinhamos.

A Lei Complementar no 123/06, com a redação atualmente em vigor, adota dois mecanismos para promover exclusóes setoriais. No primeiro, recusa-se expressamente a qualificar a empresa como Meps e, assim, impede o gozo de todas as medidas favoráveis previstas na lei; no segundo, menos abrangente, um pouco menos dramático e que congrega o maior número de atividades, mantém a qualificação e os poucos benefícios não tributários previsto no estatuto, mas impede a opção pelo regime favorecido de tributação, onde estão os maiores incentivos para as pequenas empresas.

As instituiçóes financeiras - cuja exclusão, por razões de tamanho do presente artigo, não será aqui analisada de forma mais pormenorizada - se enquadram no primeiro caso, conforme art. $3^{\circ}, \$ 4^{\circ}$, inciso VIII, da LC n ${ }^{\circ} 123 / 06$; as demais, no segundo. As

ocorrida no Brasil desde a promulgação da Constituição de 1988, influenciando diretamente as esferas federativas" (2007, p. 5). 
atividades, que impedem as empresas de usufruírem do Simples Nacional, estão elencadas em vários incisos do art. 17; são elas: (i) importação e fabricação de automóveis e motocicletas; (ii) geração, transmissão, distribuição e comercialização de energia elétrica; (iii) importação de combustíveis; (iv) transporte intermunicipal e interestadual de passageiros; (v) produção e venda no atacado de fumo, bebida, armas e muniçóes; e (vi) factoring.

Estamos seguros, contudo, de que nenhuma dessas exclusôes possui fundamento jurídico sustentável. As razóes encontradas nos trabalhos acadêmicos inspecionados para justificar muitas delas não convencem. Nenhum autor nacional foi capaz de identificar as reais motivaçóes para a positivação dessas exclusóes, motivaçóes estas, ilegítimas do ponto de vista político, e inconstitucionais sob o aspecto jurídico. Como demonstraremos a seguir, ao analisar os setores automobilístico, de transporte de passageiros, de energia, de fabricação de armamento, bebidas e produtos de tabaco, as exclusóes buscam apenas reservar, para o grande capital, setores econômicos lucrativos ou elos-clave de importantes cadeias produtivas.

\section{Setor Automobilístico}

Principiamos nossa análise pelo setor automobilístico. A única explicação plausível para os fabricantes e importadores de automóveis e motocicletas serem excluídos do Simples Nacional é o interesse das grandes corporaçóes. A atual disciplina jurídica elimina qualquer risco de um pequeno empreendedor nacional, incentivado pelo tratamento tributário diferenciado, venha adquirir tamanho e musculatura suficientes para competir no mercado nacional e até no internacional com os grandes grupos estabelecidos, e de que pequenas fábricas, mas em número elevado, sejam capazes de subtrair parcela significativa desse negócio.

Os grandes conglomerados se estruturam para liberar aos pequenos empreendimentos os demais pontos da cadeia - da fabricação de peças à venda a varejo dos veículos -, mas atuam firme e vigorosamente para dominar o elo essencial de todo o processo (a montagem), por meio do qual podem, via mercado, numa relação econômica desigual, absorver a maior parte do lucro formado nas diversas etapas ocupadas pelos pequenos empreendimentos ${ }^{5}$. Nesse ardil para manter sob o seu domínio o elo-vital de toda a cadeia, não se satisfazem com as imensas barreiras naturais de entrada para os empreendedores de parcos recursos e atuam para as ampliar por meio da lei. Não há dúvida sobre a potencial dificuldade para as pequenas iniciativas desenvolverem projetos economicamente viáveis

5 No mesmo sentido, é oportuna a observação do Professor de Sociologia da UFRJ Carlos Montaño: "A PeME satélite vende barato sua mercadoria, que serve de insumo à grande empresa, para esta elaborar, ou apenas comercializar, seu produto, vendendo-o à população a preços muito mais elevados" (1999, p. 43). 
de produção automobilística, mas a manutenção das complexas obrigaçôes jurídicas torna o árduo, impossível; transforma grandes obstáculos em barreiras intransponíveis. Com isso, assegura-se juridicamente a posição hegemônica das grandes corporaçóes e, nessa estratégica, ainda mais importante é a manutenção de elevados obstáculos à importação. Por isso, os importadores de automóveis e motocicletas (diferentemente das pequenas empresas que promovem a importação de quase todos os demais produtos) também foram excluídos da mitigação dos encargos jurídicos tributários.

Aliás, não é recente a enorme influência das grandes montadoras sobre a formulação legislativa em desfavor dos agentes econômicos de menor envergadura. Como exemplo, a Lei $\mathrm{n}^{\circ}$ 6.729, de 28 de novembro de 1979, que "dispóe sobre a concessão comercial entre produtores e distribuidores de veículos automotores de via terrestre", estabelece regras claramente mais favoráveis às montadoras em detrimento das concessionárias. De um lado, são várias as obrigaçóes impostas aos revendedores, como a exclusividade no comércio de veículos novos (só podem negociar os usados das outras marcas e, ainda assim, essa "concessão" se coaduna com o propósito de potencializar a venda dos automóveis zeroquilômetro) e a manutençáo de estoque mínimo de veículos e componentes, por outro lado, permite aos concedentes (montadoras) realizar vendas diretas (art. 15) a grandes compradores, como a Administração Pública e as locadoras de veículos.

Alguns pesquisadores buscam legitimar esse tipo de exceção setorial pelo suposto fato de dizerem respeito a atividades próprias de grandes grupos empresariais ${ }^{6}$. Ora, se esse tipo de argumento fosse válido para impedir o favorecimento das pequenas empresas, com maiores razóes, deveriam ter sido excluídas também refinarias de petróleo e usinas siderúrgicas. No caso específico da fabricação de veículos automotores, nem sequer precisamos ir tão longe para demonstrar a extravagância da explicação; afinal, se o motivo fosse legítimo, seria ainda mais justificável excluir os fabricantes e importadores de caminhóes, tratores, trens, aeronaves e embarcaçóes.

Todavia, esses setores não foram excluídos provavelmente porque os grupos econômicos neles atuantes julgam que seu nicho de negócios já naturalmente impede o ingresso de pequenas empresas por maiores que possam ser os incentivos governamentais - como a área de atuação da EMBRAER em razão do perfil dos seus produtos, cujo valor unitário supera várias vezes o limite máximo de enquadramento calcado na receita bruta anual - e, portanto, não precisariam envidar esforços para levantar também obstáculos jurídicos à

6 É o caso de KARKACHE: "Em linhas gerais, os casos de vedação costumam prevenir que recebam tratamento favorecido e diferenciado: (...) atividades econômicas próprias às grandes corporaçôes, por necessidades econômicas ou jurídicas, como as instituiçôes financeiras, fábricas de automóveis, entidades da Administração Pública, serviços de comunicação, grandes transportadoras (interestaduais e intermunicipais), energia elétrica, importação de combustíveis dentre outras” (2009, p. 242; nosso negrito). 
entrada de pequenos empreendimentos, ou em razão de não haver (ainda) um lobby de grandes empresas apto a obter o privilégio legal.

Vários argumentos refutam a falaciosa posição de haver atividades próprias aos altos investimentos e economicamente incompatíveis com a atuação das empresas menores, assim como não há qualquer valor constitucional que legitime o não favorecimento aos pequenos como meio de garantir a participação exclusiva do grande capital em qualquer dos setores econômicos nacionais.

Se determinadas atividades já fossem, per si, capazes de repelir pequenas iniciativas, a exclusão legal seria despicienda. Não faz sentido deôntico impedir a opção pelo regime favorecido sob essa justificativa, porque, se as próprias características do negócio fossem, de fato, impeditivas para a atuação de pequenos, a vedação legal seria absolutamente desnecessária. Afinal, dos três tipos modais descritivos das condutas humanas - possíveis, impossíveis e necessárias -, o direito só alcança as primeiras. É totalmente destituído de função jurídico-pragmática proibir, obrigar ou permitir alguém de respirar (conduta necessária) ou de voar desprovido de qualquer aparato tecnológico (conduta impossível). Ao proibir uma conduta sob a falaciosa justificativa de ser impossível, o legislador busca, na verdade, juridicamente impedir algo que, apesar de difícil, seria possível.

Além disso, com os avanços tecnológicos cada vez mais acelerados, o legislador não tem aptidóes para antever as atividades que poderão ser exercidas, no futuro, também por empresas de pequeno porte. Na verdade, sempre haverá perspectivas, por mais complexas e custosas que determinadas atividades aparentam ser, que pequenas empresas, dotadas de capacidades inventivas, venham a desenvolver métodos mais eficientes e produtos mais baratos ou que possam preencher nichos específicos de mercado; logo, o legislador não pode tolher de antemão essas iniciativas, sob pena de violar diversos ditames constitucionais, a começar pelo Desenvolvimento $\mathrm{Nacional}^{7}$. Para ficarmos num único exemplo de como uma política desse tipo poderia ser nefasta; na indústria da extração de petróleo, pretensamente passível de ser considerada modelo de atividade típica dos grandes investimentos - afinal, as indústrias petrolíferas sempre encabeçaram as relações das maiores empresas mundiais ${ }^{8}$-, há intensa participação de pequenos empreendimentos nos Estados Unidos, onde são responsáveis por mais de 50\% dos empregos do setor, conforme reportagem da Revista Exame (MUNIZ, 2005). No mesmo artigo desse periódico, é relatada a iniciativa brasileira da Agência Nacional do Petróleo (ANP) de fomentar a participação de pequenas empresas na extração, em terra, nas áreas denominadas "acumulaçôes marginais inativas".

7 Art. 3o, inciso II, da Constituição Federal: “Constituem objetivos fundamentais da República Federativa do Brasil (...) garantir o desenvolvimento nacional”.

8 No rol das dez primeiras por valor de faturamento elaborado pela Revista Fortune em 2012, conforme reportagem de Daniela Barbosa (2013), são quatro: Shell, ExxonMobil, BP, e a CNPC, respectivamente, nas primeira, segunda, quarta e sexta posiçốes. 
De mais a mais, se todas essas consideraçóes não bastassem para refutar de vez o argumento de haver setores economicamente viáveis apenas para os macro-empreendimentos, a evidência empírica não deixa dúvidas sobre a erronia. No campo automobilístico, são vários os exemplos de grandes montadoras que tiveram por origem justamente pequenos negócios. Dentre muitos outros, é o caso da Hyundai ${ }^{9}$, da $\mathrm{Chrysler}^{10}$ e da Honda; esta última impulsionada pela política japonesa do pós-guerra de fomentar a criação e o desenvolvimento de empresas de menor porte. A referida montadora foi fundada em 1947 como uma pequena fabricante de bicicletas motorizadas e, mesmo numa época em que a montadora nipônica Toyota já era uma grande corporação, pode crescer a passos largos e céleres na economia japonesa e global. Em poucos anos, se tornou a maior fabricante de motocicletas do mundo para logo depois também se posicionar entre as grandes na produção de automóveis.

Esses exemplos deixam claro que, do ponto de vista exclusivamente econômico, a entrada no referido setor não é impossível para pequenas empresas e que estas podem alcançar os estágios mais avançados de porte e produção. No nosso País, porém, a legislação, sobretudo a tributária, estabelece barreiras praticamente intransponíveis para a criação e o desenvolvimento de montadoras nacionais a partir de pequenas iniciativas. Julgamos não ser por acaso, pois, que o Brasil, dentre todas as 10 (dez) maiores economias mundiais, é o único que não possui sequer uma só montadora nacional. Para ficarmos com apenas um exemplo por país: nos Estados Unidos, podemos citar a Ford; na China, a Chery; no Japão, a Toyota; na Alemanha, a Volkswagen; na França, a Renault; no Reino Unido, a Land Rover; na Itália, a Fiat; na Rússia, a Lada; por fim, na Índia, a Tata.

É natural que grandes grupos predominem nos setores em que há elevadas economias de escala e naqueles cujos produtos são de alto valor, mas mesmo nestas atividades econômicas o ingresso de pequenos empreendimentos não pode ser totalmente descartado.

Por óbvio, uma empresa inicialmente pequena não seria capaz de competir com a EMBRAER, nem com os estaleiros construtores de navios de carga. Na verdade, tampouco um empreendimento de porte médio teria condiçóes para tal. Todavia, não é impossível a uma empresa ainda mirrada construir pequenos barcos e aeroplanos e, à medida que fosse crescendo, passasse a produzir bens de porte e valor mais elevados até atingir o patamar dos maiores navios e aeronaves.

9 São dignas de nota as palavras de SOLOMON, pág. 368: "Hyundai, por exemplo, foi fundada pelo proprietário de uma oficina de automóveis que consertava caminhóes do exército norte-americano e, em seguida, se expandiu durante a Guerra da Coréia" (1986, p.368).

10 Conforme reportagem do "Estado de São Paulo" de 14/03/1929 (RECORDE. O Estado de S. Paulo, São Paulo, 14 mar. 1929), a Chrysler surgiu como uma pequena empresa em 1925 e já em 1929 era a terceira maior fabricante de automóveis do mundo. 
Do mesmo modo, nos setores em há reduçóes significativas de custo mediante ganhos de escala, como a produção de automóveis, o ambiente é mais propício à atuação dos grandes empreendimentos, mas nada impede que pequenas empresas, através da diferenciação de produtos e do atendimento a consumidores com exigências específicas, sejam capazes de prosperar e, posteriormente, se desenvolver para atingir níveis mais amplos de produção.

Nesse sentido, pequenas empresas podem adotar iniciativas capazes de romper barreiras tecnológicas, impulsionar com mais intensidade o desenvolvimento econômico e de desafiar paradigmas consolidados por grandes conglomerados empresariais, como a produção, a baixo de custo, de aeroplanos pessoais e até de veículos terrestres capazes de se converter em aeronaves, como nos reportou Danny Hakim, no The New York Times: "Algumas pequenas empresas já estão desenvolvendo carros voadores, como a Pal-V da Holanda, que tem por objetivo lançar no mercado até 2016, por U\$300.000,00, um carro pequeno capaz de se transformar num helicóptero" ${ }^{11}$.

Até nos campos da siderurgia, da química e da exploração de petróleo, é possível os pequenos se sustentarem. Siderúrgicas de porte acanhado podem se especializar na elaboração de ligas exclusivas, diminutos laboratórios têm a possibilidade de formular produtos químicos especiais e petrolíferas de porte pequeno são capazes de explorar acumulaçóes marginais em terra. Por conseguinte, não há nenhum setor econômico a ser previamente considerado exclusivo de grandes empresas. Sempre existirá a possibilidade de ingresso de empreendimentos menores liderados por um empresário engenhoso.

A proibição legal não é explicada por uma simples ignorância do legislador acerca da viabilidade de pequenos empreendimentos florescerem em qualquer ramo da atividade econômica. Tudo nos leva a crer que o impedimento normativo advém da pressáo política de grandes grupos econômicos, alguns dos quais oriundos de pequenas empresas e, portanto, conhecedores dessa possibilidade. Por isso, defendem acirradamente, com o ilegítimo aval do legislador nacional, sua posição hegemônica.

\section{Setor de Transporte}

A exclusão dos fabricantes e importadores de automóveis e motocicletas não é exemplo isolado de uso escuso da lei para defesa ilegítima e inconstitucional dos interesses de grandes corporações em detrimento dos pequenos empreendimentos e nem é o mais evidente.

11 Tradução livre de "Some small companies are already developing flying cars, like Pal-V of the Netherlands, which aims to bring a small car that can turn into a helicopter onto the market by 2016, priced at around \$300,000" (2014). 
Na redação original da Lei Complementar no 123/06, as Mpes que se dedicassem ao serviço de transporte intermunicipal e interestadual de passageiros não podiam se beneficiar dos incentivos tributários do Simples Nacional (art. 17, VI). Houve uma evolução desde então. A Lei Complementar no 147, de 8 de agosto de 2014, passou a permitir o ingresso no sistema tributário favorecido daquelas que prestassem esses serviços "na modalidade fluvial ou quando possuir características de transporte urbano ou metropolitano ou realizar-se sob fretamento contínuo em área metropolitana para o transporte de estudantes ou trabalhadores". Continuam, contudo, excluídas as demais modalidades de transporte.

Mas, afinal, que razão legítima poderia fundamentar o impedimento de pequenas empresas, atuantes no transporte interestadual e intermunicipal de passageiros, optarem pelo regime unificado de tributação?

Mais uma vez, há autores que, equivocadamente, consideram impossível a atuação dos empreendimentos de menor porte nesse ramo de negócios. É o caso de FRACAROLLI, que entende ser necessário grande capital para o exercício dessa atividade. Nas suas palavras, "o próprio ramo de transportes e das comunicaçóes é incompatível com a natureza da pequena empresa, por exigir um grande capital, conhecimento técnico e tecnológico aprimorado e muitos empregados" (1976, p.123).

No entanto, novamente, a evidência empírica infirma essa posição. A Viação 1001, por exemplo, com uma frota atual de mais de 1.200 (mil e duzentos) veículos, foi fundada na década de 1940 com um único ônibus e por um jovem de apenas 18 (dezoito) anos de idade (Jelson da Costa Antunes) ${ }^{12}$.

Ademais, como justificar esse impedimento apenas para o transporte de passageiros, mas não para o de carga? A distinção de tratamento nos leva a crer que a ingerência política do grupo de empresas pertencentes ao primeiro setor foi mais eficaz que a do segundo.

\section{Setor de Energia}

Não menos estapafúrdias e fruto da influência dos grandes grupos econômicos que dominam alguns dos setores nacionais, são as exclusóes das atividades de geração, transmissão, distribuição e comercialização de energia elétrica, e de importação de combustíveis.

No caso das pequenas geradoras de energia, não só inexistem razóes aptas a justificar o impedimento para usufruírem do sistema favorecido tributário, como há diversos argumentos específicos a favor.

12 Informaçóes obtidas no próprio sítio da empresa: < http://www.autoviacao1001.com.br>. Acesso: 11 jan. 2013. 
As denominadas "pequenas centrais hidrelétricas" (PCH), por exemplo, causam comparativamente menos impactos ambientais. Logo, o incentivo jurídico à implantação desses empreendimentos traz significativa colaboração para concretizar o preceito constitucional da "defesa do meio ambiente, inclusive mediante tratamento diferenciado conforme o impacto ambiental dos produtos e serviços e de seus processos de elaboraçáo e prestação", previsto no art. 170, inciso VI, da CF.

As $\mathrm{PCH}$ possuem ainda outras vantagens. Sua construção é mais rápida (a média é de dois anos para uma $\mathrm{PCH}$ e de cinco para uma grande hidrelétrica) e, portanto, são uma opção de resposta mais célere para crises energéticas, bem como colaboram de forma eficiente com o sistema interligado no atendimento às demandas de pequenos centros urbanos e áreas rurais (ANEEL, 2012). Ademais, a dispersão da geração traz segurança ao sistema ao reduzir sua dependência das grandes unidades, além de reduzir os gastos e os riscos da transmissão de longa distância. Por operarem, em sua maioria, pelo modelo "a fio d'água", as PCH não acarretam deslocamentos populacionais significativos, sejam urbanos, rurais ou de povos indígenas; e, pela mesma razão, causam menores danos ao patrimônio cultural e a sítios arqueológicos e paleontológicos. Com efeito, até mesmo nas $\mathrm{PCH}$ com reservatórios, em razão da sua pequena dimensão ${ }^{13}$, os danos são comparativamente menores que os causados pelas grandes hidrelétricas. Além disso, esses pequenos reservatórios criam, nos municípios, áreas de lazer para a população local e novos pontos de atração turística capazes de impulsionar o desenvolvimento do seu entorno.

Com tantas vantagens, esses empreendimentos de pequeno porte, no setor de geração de energia elétrica, foram incentivados por políticas governamentais específicas, como a isenção da compensação financeira pela utilização de recursos hídricos (Lei no 7.990/89, art. 4º, inciso I; e Lei no 9.427/96, art. 26, $\$ 4^{\circ}$ ), mas “inexplicavelmente” foram banidas do Simples Nacional. Essa mesma desarrazoada obliteração legal deixa de incentivar o surgimento de iniciativas, que, apesar de pequenas quanto ao porte, poderiam desenvolver novas tecnologias relativas a diversificadas fontes de energia elétrica - como a solar, a eólica e a biomassa - com potencial para produzir impactos ainda mais positivos que os identificados nas PCH.

\section{Setores de Fabricação de Armas, Bebidas e Tabaco}

Com relação aos setores de produção e comércio de armas, bebidas e tabaco, a exclusão, numa abordagem apressada e superficial, parece possuir algum sentido. Há um manto de legitimidade jurídica. SOTTO, por exemplo, ao analisar a redação original do

13 Conforme BOURGES, a área alagada deve se limitar a $3 \mathrm{~km}^{2}$ quando exclusiva para geração de energia, ou $13 \mathrm{~km}^{2}$ no caso de múltiplos usos (2009, p.19). 
inciso $\mathrm{X}^{14}$ (art. 17 da Lei Complementar no 123/06), que excluía, não só os fabricantes e atacadistas desses produtos, mas também de todos aqueles tributados pelo IPI com alíquota específica ou superior a 20\%, defendia a inconstitucionalidade da medida relativamente aos fabricantes de bens supérfluos. Nas suas palavras:

[...] há que se ponderar que a produção ou comercialização de produtos supérfluos não é dado suficiente para descaracterizar a hipossuficiência econômica da sociedade empresária de modo a justificar o afastamento do tratamento tributário diferenciado.

Pondere-se que os objetivos almejados pelos artigos 170, IX e 179 da Constituição da República não são unicamente econômicos, mas possuem uma forte carga social, proteger a livre iniciativa como meio de promover a criação de novos postos de trabalho e diminuir as desigualdades sociais. Assim, sob esse prisma, há que se reconhecer que tanto as empresas produtoras e comerciantes de produtos essenciais quanto as de produtos supérfluos são, do mesmo modo, pólos geradores de emprego e de renda.

Assim, no que tange à harmonização dos princípios da essencialidade e do tratamento diferenciado e favorecido ao empresário de pequeno porte, medida mais razoável e proporcional seria a introdução, no SIMPLES NACIONAL, de patamares diferenciados de alíquotas de IPI para os produtos industrializados como supérfluos (2007, p.96-97).

No entanto, assume posição diametralmente oposta quanto a bebidas, fumo e armamentos:

$\mathrm{O} \$ 4^{\circ}$ do ART. 220 da Constituição Federal impôs severas restriçóes à propaganda comercial de bebidas e cigarros, em defesa do direito à saúde. Assim, o fomento à produção de bebidas e cigarros, ainda que por micro e pequenas empresas, é incompatível com disposição expressa da Carta Magna, devendo, no caso, prevalecer a proteção à saúde, direito de todos e dever do Estado, a ser garantido mediante políticas sociais e econômicas que visem, entre outras medidas, a reduçâo do risco de doença e de outros agravos, de acordo com o artigo 197 da Constituiçáo da República.

As armas, do mesmo modo, têm tido sua produção e comercialização progressivamente restringida pela União Federal, não só como medida de segurança como também de saúde públicas. Seria, assim, um contra-senso impor medidas restritivas ao comércio de armas, por um lado, e, por outro, conferir tratamento tributário favorecido aos fabricantes e comerciantes de armamentos, ao arrepio do interesse público $(2007,97)$.

14 Segue a referida redação: "que exerça atividade de produção ou venda no atacado de bebidas alcoólicas, cigarros, armas, bem como de outros produtos tributados pelo IPI com alíquota ad valorem superior a $20 \%$ (vinte por cento) ou com alíquota específica”. 
Essa exclusão, apesar de possuir um discurso justificador mais persuasivo, como o visto acima, de proteger a saúde, tem o mesmo objetivo das anteriormente analisadas: a reserva estratégica para grandes corporações. No caso específico, são assegurados mercados altamente lucrativos por se tratarem de produtos, cujo consumo é impulsionado pelo vício (cigarros e bebidas) ou por compras governamentais (armamento).

Isso fica bem claro, principalmente, com as redaçóes do inciso X, posteriormente, dadas pelas Leis Complementares no 127/07 e 128/08, que mantiveram a exclusão “apenas" para os fabricantes e comerciantes atacadistas de bebidas, tabaco e armamento. Afinal, se o intento fosse desestimular o consumo desses itens, não haveria razão para manter o favorecimento justamente para o braço do varejo. Mas como o escopo não é esse, e sim o de garantir ao grande capital o predomínio sobre os pontos-chave de setores tấo lucrativos, a lei não pode eliminar a capilaridade da venda ao consumidor, tão necessária para o escoamento da produção das grandes empresas atuantes nesses ramos de negócio.

Por outro lado, poderia ser alegado que a exclusão dos varejistas de bebidas e tabaco acarretaria perdas sociais não compensáveis com os ganhos advindos do desestimulo ao consumo desses itens. Bares, restaurantes, padarias, mercearias e pequenos supermercados não vendem exclusivamente esses itens, mas a sua supressão do leque de produtos oferecidos aos seus clientes praticamente inviabilizaria o negócio. Ora, como poderia ser possível a um bar operar sem oferecer bebidas no seu cardápio? Diriam alguns. Tal medida, de um lado, acarretaria a mortalidade daqueles que tentassem cumprir com rigor a lei para se manterem no sistema favorecido e, conseqüentemente, causaria grandes perdas de postos de ocupação no setor; e, de outro, levaria muitos à informalidade, não necessariamente quanto à situação jurídica do estabelecimento, mas, ao menos, no tocante à venda desses itens. Assim, essa medida, em relação a uma parte dos destinatários, causaria mais danos que benefícios e, quanto à outra, seria ineficaz.

Esse tipo de alegação, contudo, não pode prosperar na venda a varejo de armas e muniçốes. Além de reunirem um número infinitamente menor de estabelecimentos em relação àqueles que oferecem bebidas e tabaco, o que limitaria drasticamente qualquer perda de postos de trabalho no caso de a alteração da tributação acarretar a falência de parte dessas empresas, o caráter exclusivo da atividade e os rigorosos controles pelos órgãos de segurança inviabilizariam qualquer tentativa de burla ao controle fiscal por meio da venda sem nota. O comércio desses produtos é da própria natureza do negócio desses varejistas, diferentemente de bares, mercearias e restaurantes, em razão do caráter diversificado das suas vendas.

A permanência no regime favorecido dos varejistas desses bens nos revela que prestigiar a saúde da população não foi o escopo para a exclusão dos fabricantes e atacadistas. A razão oculta, assim como nas hipóteses anteriormente analisadas, nos setores automobilístico, de energia e de transporte, foi a de proteger cartéis formados por grandes 
empresas ao manter elevadas barreiras à penetração dos pequenos capitais nos elos-vitais de negócios tão lucrativos.

Na lógica dessa mesma estratégia, a Lei $n^{\circ} 12.598$, de 22 de março de 2012, fruto da conversão da MP n ${ }^{\circ}$ 544/2011, estabeleceu "normas especiais para as compras, as contrataçôes e o desenvolvimento de produtos e de sistemas de defesa", e criou a assim denominada "Empresa Estratégica de Defesa" (EED), fornecedora de bens e serviços para o sistema de defesa nacional, dentre os quais, armas e muniçôes, conforme expressamente previsto no art. 2, inciso I. Para a EED foi instituído o "Regime Especial Tributário para a Indústria de Defesa” (RETID), por meio do qual se favorece de várias desoneraçóes fiscais, como a isenção (alíquota zero) de diversos tributos na aquisição interna e na importação de insumos.

Por disposição expressa $\left(\$ 6^{\circ}\right.$ do art. $\left.8^{\circ}\right)$, não podem se enquadrar como EED, os optantes do Simples Nacional. Evidentemente, pelas próprias regras da Lei Complementar 123/06, não há fabricantes de armamento nessa condição. O RETID, porém, vai além da produção bélica. Esse regime favorecido abarca um conjunto bem mais amplo de atividades que engloba, desde a complexa produção de equipamentos de comunicação, até a singela elaboração de peças de roupa (fardamento), as quais poderiam ser fornecidas por pequenas oficinas, sem qualquer risco de comprometer a segurança nacional do País, o que torna evidente que esse regime não foi inspirado por tal objetivo ou por qualquer outro constitucionalmente legitimado.

O objetivo foi concentrar na mão de poucas e grandes empresas um setor altamente lucrativo, cujos ganhos são ainda mais ampliados por meio de desoneraçóes fiscais especificamente dirigidas. Isso fica claramente demonstrado ao verificarmos que a tática de aumentar o degrau de entrada para esse mercado não foi direcionada apenas para as Mpes optantes do Simples Nacional.

Num ardil redacional, que impede o público leigo de verificar os destinatários da exclusão, o já citado $\$ 6^{\circ}$ do art. $8^{\circ}$ afastou também as demais micro e pequenas empresas, bem como as empresas de porte médio. Para fins de análise, reproduzimos, abaixo, o referido dispositivo:

As pessoas jurídicas optantes pelo Regime Especial Unificado de Arrecadação de Tributos e Contribuiçóes devidos pelas Microempresas e Empresas de Pequeno Porte - Simples Nacional, de que trata a Lei Complementar $n^{\circ} 123$, de 14 de dezembro de 2006, e as pessoas jurídicas de que tratam o inciso II do caput do art. $8^{\circ}$ da Lei $n^{\circ} 10.637$, de 30 de dezembro de 2002, e o inciso II do caput do art. 10 da Lei no 10.833 , de 29 de dezembro de 2003, não podem habilitar-se ao Retid.

Nos termos do disposto acima, além das Meps optantes do Simples Nacional, também não podem gozar dessas benesses as pessoas jurídicas de que tratam dispositivos de outras duas leis. Essas leis, no entanto, foram as que implantaram a não-cumulatividade 
para as contribuiçôes do PIS e da Cofins e os dispositivos referidos estabelecem que as pessoas jurídicas tributadas pelo lucro presumido devem permanecer na sistemática anterior cumulativa. A tributação pelo lucro presumido é aquela que simplifica a apuração do imposto sobre a renda (IR), a qual é destinada às Mpes não contempladas pelo Simples Nacional e às empresas de porte médio, cuja sobrevivência é praticamente impossível sob as complexas regras da tributação do IR pelo lucro real.

Em suma, o RETID, que contempla com favores tributários os fabricantes de bens, inclusive armamentos, a serem adquiridos pelas nossas Forças de Segurança, tem por destinatário apenas grandes empresas. Ademais, o legislador se esforçou para dificultar ao máximo que esse expediente pudesse ser percebido pelo público leigo. Para afastar as empresas de pequeno e médio porte, ao revés de fazê-lo diretamente na lei que instituiu o RETID, utilizou uma longa cadeia de referências legais.

Se a defesa da saúde da população tivesse sido o valor legitimador para a exclusão do Simples Nacional de pequenos fabricantes de armas e munições, como justificar a concessão de incentivos fiscais específicos para esse setor? Mais: que argumento legítimo poderia fundamentar a proibição do gozo dos incentivos do RETID pelos optantes do lucro presumido, que são justamente as micro, pequenas e médias empresas? Ou seja, pequenos fabricantes de armas e muniçóes foram juridicamente aniquilados, pois estão legalmente proibidos de usufruir os incentivos tributários setoriais e os estabelecidos em razão do seu menor porte econômico.

Tudo isso nos conduz à conclusão de que a exclusão dos pequenos fabricantes de armas e munições do Simples Nacional não foi orientada pela política de proteção da saúde, mas arquitetada dentro de um conjunto de medidas legais dirigidas a reservar a grandes grupos econômicos o lucrativo setor da produção de armamento.

Se tudo isso não fosse suficiente para refutar a assertiva de que a saúde é o valor constitucional perseguido pelo conjunto de exclusóes estampadas no inciso X, art. 17, da LC n 123/06, espancamos de vez esta alegação ao verificamos que, até a recente modificação empreendida pela Lei Complementar no 147/14, não só as bebidas alcoólicas estavam elencadas no rol proibitivo, mas também e de forma expressa "refrigerantes, inclusive águas saborizadas gaseificadas" (no item " 2 " da alínea "b” do citado inciso), "preparaçóes compostas, não alcoólicas (extratos concentrados ou sabores concentrados), para elaboração de bebida refrigerante, com capacidade de diluição de até 10 (dez) partes da bebida para cada parte do concentrado" (item " 3 " da referida alínea) e "cervejas sem álcool” (item “4”) 15 .

15 Para uma visão completa do conjunto de exclusôes a que fazemos referência, segue a transcrição completa do dispositivo com os seus desdobramentos: "Art. 17. Não poderão recolher os impostos e contribuiçōes na forma do Simples Nacional a microempresa ou a empresa de pequeno porte: (...) X-que exerça atividade de produção ou venda no atacado de: a) cigarros, cigarrilhas, charutos, filtros para cigarros, armas de fogo, 
Poderia ainda se aventar que esse menoscabo legal adviria de interesses arrecadatórios estatais e não das grandes corporaçóes privadas preocupadas em manter a dominação sobre mercados estratégicos. Nesse caso, interessaria ao Fisco concentrar em grandes e poucas empresas as atividades mais lucrativas e de elevada tributação, mais propensas, pois, à sonegação. Ao promover essa concentração, poderia estabelecer controles mais eficientes e menos onerosos para a máquina pública, como a selagem de cigarros, vinhos e bebidas destiladas, e os medidores de vazáo para cervejas e refrigerantes.

Não descartamos a possibilidade de tais motivaçôes, mas são igualmente ilegítimas e inconstitucionais, pois razóes de eficiência fiscal podem orientar a formulação legislativa, mas não a ponto de inviabilizar, em qualquer dos setores da atividade econômica, o cumprimento dos escopos extrafiscais norteadores do regime jurídico a ser dispensado às pequenas unidades produtivas. Todavia, em razão de haver tantos setores lucrativos - muitos dos quais beneficiados por polpudas desoneraçóes fiscais e alimentados por compras governamentais, como o de armas e até o de fabricação e comércio de computadores para uso educacional (Lei $\mathrm{n}^{\circ}$ 12.249/10) - excluídos do alcance das pequenas empresas e até das médias, estamos seguros ao afirmar que esse escuso interesse fiscal não é o único norteador dessas exclusóes estapafúrdias. Na verdade, possuímos elementos suficientes para afirmar que há, ou um conluio entre o Estado, na sua voracidade arrecadadora, e as grandes corporaçóes, no seu afã de dominação dos mercados para obter lucros extraordinários, ou, ao menos, um equilíbrio de interesses hegemônicos; e dados empíricos reforçam nossa conclusão.

Abaixo, segue tabela confeccionada com informaçóes colhidas das demonstraçóes de valor adicionado da principal fabricante nacional de bebidas, a "Companhia de Bebidas das Américas" (AMBEV), e que foram divulgadas pela própria empresa no seu site www. ambev.com.br (acesso em 31/08/2014).

\begin{tabular}{||l|l|c|c|c|c||}
\hline \hline A & \multicolumn{1}{|c|}{ Ano } & $\mathbf{2 0 1 3}$ & $\mathbf{2 0 1 2}$ & $\mathbf{2 0 1 1}$ & $\mathbf{2 0 1 0}$ \\
\hline B & Receita bruta de vendas & 53.577 & 50.373 & 42.828 & 39.437 \\
\hline C & Tributos & 16.990 & 16.491 & 14.371 & 12.766 \\
\hline D & $\begin{array}{l}\text { Remuneração do Capital } \\
\text { Próprio }\end{array}$ & 11.354 & 10.642 & 8.719 & 7.619 \\
\hline E & Margem da tributação (C/B) & $31,71 \%$ & $32,73 \%$ & $33,55 \%$ & $32,37 \%$ \\
\hline F & Margem de ganho (D/B) & $21,19 \%$ & $21,12 \%$ & $20,35 \%$ & $19,31 \%$ \\
\hline \hline
\end{tabular}

(Valores em R \$ milhóes)

muniçóes e pólvoras, explosivos e detonantes; b) bebidas a seguir descritas: 1 - alcoólicas; 2 - refrigerantes, inclusive águas saborizadas gaseificadas; 3 - preparações compostas, não alcoólicas (extratos concentrados ou sabores concentrados), para elaboração de bebida refrigerante, com capacidade de diluição de até 10 (dez) partes da bebida para cada parte do concentrado; 4 - cervejas sem álcool”. 
Os valores registrados na linha "C" englobam todos os tributos (federais, estaduais e municipais). A Remuneração do Capital Próprio (linha "D”) corresponde à soma dos dividendos, dos juros sobre capital próprio e os lucros retidos, ou seja, à parcela da geração de caixa que reverte a favor dos sócios da companhia.

Nos últimos quatro anos, a margem de ganho dos sócios sobre a receita bruta da atividade, ou seja, sem a dedução de tributos, manteve-se praticamente constante no elevado patamar de 20\%. Esse padrão de ganho é sobremaneira alto, especialmente, ao se compararmos com o percentual de $8 \%$ legalmente adotado para a aferição do lucro presumido das pequenas e médias empresas.

Ademais, essa margem extremamente polpuda foi obtida a despeito do substancioso ônus fiscal, que representou, para os mesmos anos, mais de $30 \%$ da receita total de vendas.

Como forma de ilustrar o que isso representa, para cada $\mathrm{R} \$ 100,00$ de vendas da AMBEV, o Estado ficou com $\mathrm{R} \$ 32,00$, seus sócios com $\mathrm{R} \$ 21,00$, enquanto o que sobrou ( $\mathrm{R} \$ 47,00)$ serviu para remunerar tudo o mais, ou seja, todos os seus fornecedores, prestadores de serviço, financiadores, trabalhadores, etc.

Recentemente, a Lei complementar no 147 , de 7 de agosto de 2014, revogou dispositivos da Lei Complementar 123/06 que proibiam a opção pelo Simples Nacional das Mpes fabricantes de refrigerantes e de águas saborizadas.

Essa medida é um avanço, sem dúvida, porém pode representar apenas um expediente para reforçar o argumento legitimador, mas falso, de que a proteção à saúde corresponderia ao intento jurídico para a exclusão dos pequenos fabricantes de bebidas alcóolicas.

Mesmo com a modificação legal, continuamos seguros de que a saúde da população não foi a razão para manter os pequenos alambiques e os demais diminutos produtores de bebidas, desde o seu nascedouro, sob a cunha de uma legislação tributária elaborada para regular as complexas atividades empresariais dos grandes grupos econômicos.

Se o cuidado com a saúde da população tivesse, de fato, sido o eixo orientador da disposição excludente do tratamento favorecido para as pequenas empresas, como justificar a proibição também para os produtores de cerveja sem álcool? Ademais, o tratamento tributário para o setor de bebidas segue a mesma lógica do de armamentos. De um lado, os pequenos produtores são proibidos de usufruir do tratamento favorecido, que não se caracteriza como um privilégio, mas sim como um mecanismo para minimizar as múltiplas desvantagens que o próprio porte econômico já impóe aos pequenos; de outro, o legislador estabelece específicas vantagens fiscais para o setor, as quais só podem ser usufruídas por poderosos conglomerados econômicos, como o crédito presumido para investimentos em pessoas jurídicas no exterior destinado exclusivamente a algumas poucas atividades econômicas, nas quais está incluída a fabricação de bebidas (art. 87, $\$ 10$, da Lei no 12.973, de 13 de maio de 2014). 
Os dados empíricos já apontados e a estrutura jurídica da tributação setorial confirmam, com segurança, nossa hipótese do conluio (ou do equilíbrio de interesses hegemônicos em detrimento do direito dos pequenos empreendimentos), em certos ramos de negócio, entre o Estado e grandes empresas com o fito de fomentar a concentração de mercado e, conseguintemente, garantir ganhos extraordinários a serem repartidos entre os dois atores em detrimento do resto da sociedade.

Vale ainda observar, nesse sentido, que, no ranking dos 10 (dez) brasileiros mais ricos, estão 4 (quatro) do setor de bebidas, inclusive o que figura em primeiro lugar (VAZ, 2014).

\section{Conclusões}

Com a análise de alguns setores econômicos, cujas pequenas empresas atuantes estão atualmente excluídas da tributação favorecida, podemos afirmar que inexistem valores superiores capazes de justificar a mitigação do primado constitucional do tratamento favorecido. Mais: os valores alegados são, na verdade, discursos legitimadores (ainda que possivelmente náo conscientes por parte de alguns dos seus formuladores) de exclusóes motivadas por razóes que operam em desconformidade com os ditames superiores da nossa ordem constitucional, como a livre concorrência.

As vedaçóes à opção do Simples Nacional, aqui analisadas, demonstram que as desvantagens das Meps para concorrerem em condiçóes de igualdade com empresas de maior porte não decorrem exclusivamente de fatores naturais, como a dificuldade para obtençáo e o elevado custo de financiamentos bancários.

É por meio da legislação, sobretudo da tributária e até no seio do diploma que supostamente deveria se dedicar a favorecer os menores, que essas desvantagens, ao revés de serem abrandadas em cumprimento do comando constitucional, são reforçadas, freqüentemente de forma deliberada.

As exclusôes setoriais do Simples Nacional operam como método abortivo e contraceptivo das pequenas iniciativas em prol das grandes corporaçóes já estabelecidas.

\section{Referências}

ANEEL. Guia do Empreendedor de Pequenas Centrais Hidrelétricas. Disponível em <http:// www3.aneel.gov.br/empreendedor/empreendedor.htm> acesso em 18/07/2012.

BARBOSA, Barbosa. As maiores do mundo. Revista Exame, 10 jul. 2013. Disponível em $<$ http://exame.abril.com.br/negocios/noticias/as-25-maiores-empresas-do-mundosegundo-a-fortune>, acesso em 04 de julho de 2014. 
BOURGES, Fernando. Planejamento da Operação de Pequenas Centrais Hidrelétricas: Enfoque Sistêmico. Dissertaçáo de Mestrado (Engenharia Elétrica). Curitiba, UFPN, 2009.

FRACAROLLI, Luiz Machado. Pequena e média empresas: aspectos legais. São Paulo, Pioneira, 1976.

HAKIM, Danny. A Helicopter of One's Own. The New York Times, 17 JUN. 2014. Disponível em <http://www.nytimes.com/2014/06/17/science/a-helicopter-of-ones -own.html?_r=0>, acesso em 09/07/2014.

KARKACHE, Sergio. Princípio do tratamento favorecido: o direito das empresas de pequeno porte a uma carga tributária menor. Dissertação de Mestrado. Curitiba, UFPR, 2009.

MARINS, James \& BERTOLDI, Marcelo M. Simples Nacional: Estatuto da Microempresa e da Empresa de Pequeno Porte comentado. São Paulo, Editora Revista dos Tribunais, 2007.

MONTAÑO, Carlos E. Microempresa na era da globalização: uma abordagem históricocrítica. São Paulo, Cortez, 1999.

MUNIZ, Ricardo. ANP tenta atrair pequenas empresas para exploração de petróleo. Revista Exame, 14 out. 2005. Disponível em <http://exame.abril.com.br/negocios/ empresas/noticias/n0079363>, acesso em 16 de julho de 2012.

OECD (OCDE). Taxations and Small Businesses. Paris, OECD, 1994.

PELLIZZARO JÚNIOR, Roque. País coleciona natimortos entre pequenas e microempresas. Jornal Folha de S.Paulo, 09 jun. 2011. Disponível em <http://www1.folha. uol.com.br/fsp/mercado/me0906201105.htm>, acesso em 09/06/2011.

RECORDE. O Estado de S. Paulo, São Paulo, 14 mar. 1929.

RESNIK, Paul. A Bíblia da pequena empresa. Tradução de Maria Cláudia Oliveira. São Paulo, McGraw-Hill \& MAKRON Books, 1990.

SOLOMON, Steven. A grande importância da pequena empresa: a pequena empresa nos Estados Unidos, no Brasil e no Mundo. Tradução de M. R. da Cruz. Rio de Janeiro, Nórdica, 1986.

SOTTO, Débora. Tributação da Microempresa e da Empresa de Pequeno Porte. São Paulo, Quartier Latin, 2007.

VAZ, Tatiana. Veja quem são os 65 bilionários brasileiros da Forbes 2014. Revista Exame, 03 mar. 2014. Disponível em <http://exame.abril.com.br/negocios/noticias/vejaquem-sao-os-65-bilionarios-brasileiros-da-forbes-2014>, acesso em 03/09/2014.

VINYARD, Dale. Congressional Committees on Small Business. Midwest Journal of Political Science, vol. 10, nº 3 (agosto de 1966); pág. 364-377. Disponível em <http:// www.jstor.org/stable/2108891>; acesso em 28/07/2011. 